\title{
Anabases
}

ANABASES Traditions et réceptions de l'Antiquité

Walter PUCHNER, Greek theatre between Antiquity and Independence. A History of Reinvention from the Third Century BC to 1830

\section{Alain Ballabriga}

\section{OpenEdition}

\section{Journals}

Édition électronique

URL : http://journals.openedition.org/anabases/8267

DOI : 10.4000/anabases.8267

ISSN : 2256-9421

Éditeur

E.R.A.S.M.E.

\section{Édition imprimée}

Date de publication : 9 novembre 2018

Pagination : 387-390

ISSN : $1774-4296$

\section{Référence électronique}

Alain Ballabriga, «Walter PUCHNER, Greek theatre between Antiquity and Independence. A History of Reinvention from the Third Century BC to 1830 », Anabases [En ligne], 28 | 2018, mis en ligne le 09 novembre 2018, consulté le 20 janvier 2021. URL : http://journals.openedition.org/anabases/8267 ; DOI : https://doi.org/10.4000/anabases.8267

Ce document a été généré automatiquement le 20 janvier 2021.

(c) Anabases 


\title{
Walter PUCHNER, Greek theatre
} between Antiquity and Independence. A History of Reinvention from the Third Century BC to 1830

\author{
Alain Ballabriga
}

\section{RÉFÉRENCE}

Walter PUCHNER, Greek theatre between Antiquity and Independence. A History of Reinvention from the Third Century BC to 1830, Cambridge, Cambridge University Press, 2017, 355 p., 75 livres / ISBN 978-1- 107-05947-4.

1 L'auteur de ce livre, Walter Puchner, est un néo-helléniste d'origine autrichienne. Né en 1947, il est professeur émérite dans le Département d'études théâtrales de l'université d'Athènes. Spécialiste de l'histoire du théâtre dans la péninsule balkanique, il est également versé dans ce que l'on appelle en grec la «laographie ", c'est-à-dire dans l'étude ethnographique des cultures de la Méditerranée et du Sud-Est de l'Europe.

2 En introduction (p.1-15) d'un livre qui porte sur une discontinuité majeure dans la culture grecque, l'auteur, d'une façon tout à fait pertinente et nécessaire, tient à rappeler au contraire les continuités de cette culture: du fait de la spécificité de l'histoire byzantine et post-byzantine, la Grèce moderne a gardé un héritage antique plus important que l'Europe latine. Ce fait, bien connu de ceux qui connaissent à la fois la Grèce ancienne et moderne, est souvent ignoré des purs antiquisants.

3 Après cette introduction, dans un premier chapitre (p. 16-51), l'auteur envisage les évolutions du théâtre grec depuis les débuts de la période hellénistique (III ${ }^{\mathrm{e}} \mathrm{s}$. av. J.-C.) jusqu'à la fin de l'Antiquité ( $\mathrm{IV}^{\mathrm{e}}-\mathrm{VI}^{\mathrm{e}} \mathrm{s}$. ap. J.-C.). La période hellénistique est riche d'une intense activité théâtrale. Les Artistes Dionysiaques participent dans tout le monde grec à des représentations de pièces anciennes (Euripide et Ménandre entre autres) et 
de pièces nouvelles à l'occasion des Dionysies et de nombreux autres festivals. Peu à peu cette vie théâtrale, prolongeant celle de l'Athènes classique, voit la domination des mimes et pantomimes : les mimes sont des farces à la fois érotiques et satiriques où l'improvisation tient une grande part et qui font la joie aussi bien du peuple que de l'élite. Les pantomimes sont des spectacles de danse à sujet littéraire ou mythologique avec accompagnement musical. Les vieilles pièces du répertoire classique font l'objet de lectures et d'études de la part de lettrés, professeurs et étudiants.

Consacré à la période byzantine, le deuxième chapitre (p.52-111) porte sur la question controversée de l'existence ou non d'une vie théâtrale à Byzance. L'auteur évoque d'abord les continuités culturelles dans le passage du paganisme au christianisme: réinterprétées et déplacées dans le calendrier, de nombreuses festivités continuent celles de l'Antiquité. Cette persistance de traits culturels provoque des condamnations répétées lors des synodes de l'Église orthodoxe. Le vocabulaire employé par les censeurs reste celui qui était relatif au théâtre antique. Mais le sens de ces mots a changé et semble bien ne viser que des manifestations para-théâtrales, telles que danses, farces et mascarades dans les rues lors de fêtes. Quant à l'hippodrome de Constantinople, il est un centre festif lié au culte de l'empereur mais son importance tend à décliner après le règne de Justinien ( $\mathrm{vi}^{\mathrm{e}} \mathrm{s}$. ap. J.-C.). Une mention spéciale doit être faite à propos de la tragédie Christos paschôn (La Passion du Christ). Ce centon de vers d'Euripide, attribué par certains à Grégoire de Nazianze (IV s. ap. J.-C.), serait plutôt à dater du XII ${ }^{e}$ siècle. En tout état de cause, ce n'était sans doute pas un texte destiné à la représentation mais à la lecture de quelques savants capables de lire le grec d'Euripide. Par contre, traduit en grec moderne, le Christos paschôn a fait l'objet de représentations au Xx $x^{e}$ siècle, à l'occasion des fêtes de Pâques, malgré les réserves que l'Église orthodoxe continue de nourrir à l'égard de tels spectacles.

5 Le troisième chapitre (p. 112-172) envisage la réinvention du théâtre dans la Crète des $\mathrm{XVI}^{\mathrm{e}}$-XVII ${ }^{\mathrm{e}}$ siècles après sa disparition pendant près d'un millénaire. Du milieu du XVI ${ }^{\mathrm{e}} \mathrm{s}$. au milieu du XVII siècle, la Crète, sous occupation vénitienne, connaît une période de coexistence pacifique entre Crétois et Vénitiens, marquée par des mariages mixtes, une assimilation linguistique des vieilles familles vénitiennes et un puissant mouvement humaniste illustré par les hellénistes crétois. Ce contexte permet l'éclosion d'une riche littérature dramatique qui n'ignore ni Shakespeare ni Lope de Vega, même si l'influence principale vient du théâtre italien, héritier du théâtre latin, adapté au contexte culturel crétois. Un des grands noms de l'époque est Georgios Chortatsis, de Réthymno, auteur de la tragédie Erophile et de la comédie Katzourbos (vers 1600). Les comédies sont représentées essentiellement durant les festivités du Carnaval. Cette riche vie théâtrale est interrompue par l'occupation ottomane de l'île en 1669. Mais les manuscrits sont transportés dans les Îles Ioniennes qui échapperont toujours à l'Empire Ottoman. La survie de ce théâtre crétois sera aussi assurée par une tradition orale qui durera jusqu'au $\mathrm{Xx}^{\mathrm{e}}$ siècle.

6 Le quatrième chapitre (p. 173-195) porte sur la vie théâtrale dans les Îles Ioniennes du $\mathrm{XVI}^{\mathrm{e}}$ au début $\mathrm{du}$ xIX ${ }^{\mathrm{e}}$ siècle. Tout en recueillant l'héritage crétois, le théâtre des Îles Ioniennes produit des œuvres originales. Par exemple la pièce Iphigénie et Thyeste de Petros Katsaïtsis (1720-1721) est une tragi-comédie dans laquelle se fait sentir l'influence de Molière à travers la commedia dell'arte tandis que la mythologie est librement traitée pour des raisons didactiques et morales. Une autre influence importante est celle des omilies, courtes pièces populaires qui accompagnaient les 
mascarades et chants satiriques du Carnaval. Un autre genre de spectacle, plus élitiste, était fourni par l'opéra italien avec des livrets de Métastase et Goldoni en italien ou en grec.

7 Une forme toute différente de spectacle apparaît dans le chapitre 5 (p. 196-245): le théâtre des Jésuites à Constantinople et dans l'Archipel entre 1600 et 1750. Ce n'est qu'à partir des années 1970 que la découverte et l'étude des manuscrits ont rév élé l'existence de ce théâtre. À la suite du Concile de Trente et de la Contre-Réforme (milieu du xvI ${ }^{e}$ siècle), des missionnaires français et italiens, tentant de convertir les chrétiens orthodoxes de l'Empire Ottoman, créent une forme de théâtre susceptible de servir leur ambition et unique en Europe. Ce sont des pièces morales destinées à détourner leurs ouailles des immondes mascarades du Carnaval et qui s'inspirent de sujets tirés de l'Ancien et du Nouveau Testament. Avec la suppression de l'ordre des Jésuites en 1773, cette expérience théâtrale prend fin.

8 Le chapitre 6 (p. 246-262) étudie la création dramatique, essentiellement destinée à la lecture, de la fin duxvIII ${ }^{\mathrm{e}}$ et du début du $\mathrm{xIX}^{\mathrm{e}}$ siècle, époque où la réception des Lumières, prodrome de la guerre de libération (1821-1830), se fait sentir dans les divers centres culturels où l'hellénisme est bien implanté : Vienne, qui prend la relève de Venise, Bucarest et Jassy dans l'actuelle Roumanie, Odessa, création récente sur la Mer Noire. Cette réception, qui se greffe d'ailleurs sur un riche héritage byzantin et postbyzantin, conduit à un usage politique de l'Antiquité grecque. Ainsi l'olympiade de Pietro Metastasio (1698-1782) est traduite par Rhigas Velestinlis en 1797 mais ne sera jouée à Athènes qu'en 1836 au lendemain de la guerre de libération. On traduit aussi des tragédies à sujet antique de Racine, Voltaire et Alfieri. L'approche de la comédie est plus circonspecte. On préfère les comédies de mœurs de Molière et Goldoni mais aucune comédie ne sera représentée avant 1821. Une des plus célèbres est l'adaptation par Constantin Economos (Smyrne 1816) de L'Avare de Molière, qui est reprise de nos jours sur les scènes grecques, tout comme d'ailleurs l'Olympiade de Métastase.

9 Ce style théâtral se continue dans les années qui précèdent et suivent la guerre de libération de 1821-1830 (chapitre 7, p. 269-300) avec des tragédies à l'antique qui sont autant de drames historiques et patriotiques. Par exemple Polyxène (1814) de Iakovos Rizos Neroulos, un des auteurs les plus importants de la période. Mais on écrit aussi des tragédies portant sur des événements récents tels que la prise par les Turcs de Missolonghi et de l'île de Psara. Quant à la comédie, outre les thèmes ordinaires de la comédie bourgeoise, elle présente la particularité d'intervenir dans la question linguistique qui, jusqu'à la dictature des colonels (1967-1974), divise les Grecs entre partisans d'un grec puriste ou populaire : c'est encore Iakovos Rizos Neroulos qui, dans sa pièce Korakistika (1813), fait une satire des réformes linguistiques préconisées par Koraïs. Mais la comédie qui gardera un succès durable jusqu'à nos jours est Le basilic d'Antonios Matesis (Zante, 1832), drame bourgeois dont la langue simple était accessible à un large public à la différence des tragédies en grec archaïsant.

Un court huitième chapitre (p.301-314) esquisse les évolutions du XIX siècle consolidation d'un État national, européanisation, développement d'une culture bourgeoise - qui conduisirent à une vie théâtrale qui, vers la fin du XIX et le début du $\mathrm{xx}^{\mathrm{e}}$ siècle, s'est stabilisée sur le modèle des autres nations européennes, tandis qu'un épilogue (p. 315-324) synthétise les multiples ruptures et discontinuités de l'histoire du théâtre grec depuis l'Antiquité. 


\section{AUTEUR}

ALAIN BALLABRIGA

CNRS

a.ballabriga@gmail.com 